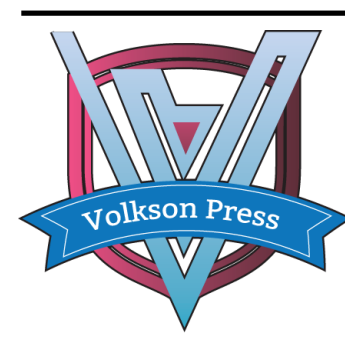

Contents List available at VOLKSON PRESS

New Materials and Intelligent Manufacturing (NMIM) DOI : http://doi.org/10.26480/icnmim.01.2018.65.68

Journal Homepage: https://topicsonchemeng.org.my/

ISBN: 978-1-948012-12-6

\title{
DESIGN OF THE DISTILLATION TOWER TEMPERATURE CONTROL SYSTEM BASED ON JX-300XP DCS
}

\author{
Zhu Jian-Jun, Dai Xing-Tuo,Wang Peng-Fei \\ Department of Automation, College of Information \&Control Engineering
}

This is an open access article distributed under the Creative Commons Attribution License, which permits unrestricted use, distribution, and reproduction in any medium, provided the original work is properly cited

\section{ARTICLE DETAILS}

\section{Article History:}

Received 26 June 2018 Accepted 2 July 2018 Available online 1 August 2018

\section{ABSTRACT}

In combination of the powerful capability of engineering computing of MATLAB and the virtual interface of AdvanTrol-Pro, the serial communication between AdvanTrol-Pro and Matlab is designed and realized by OPC technology. As the communication interface of client Matlab and Server AdvanTrol-Pro, OPC implements better communications between heterogeneous systems. This paper describes in detail its methods and concrete steps, and algorithm is verified in the control system of the distillation column in the laboratory the purpose of separately constructing object model and controller can be reached, thus effective simulation platform of theoretical research and design of control systems is provided.

\section{KEYWORDS}

Distillation column, PID, OPC, MATLAB

\section{INTRODUCTION}

This design uses the laboratory DCS distillation tower control system device object. On the hardware foundation of the experimental device. The working principle and workflow of the distillation tower temperature control system based on jx-300xp DCS are analyzed. The overall control scheme of the system is determined. The AdvanTrol-Pro software program was developed and monitored. At the same time, the SUPCON.JX server. 1 of the configuration software AdvanTrol-Pro is used as the OPC Server. The model of the system control algorithm was built using the Simulink toolbox, and the OPC interface was used for data exchange with the configuration software OPC server connection to realize the connection between MATLAB and the AdvanTrol-Pro software.

\section{DISTILLATION COLUMN EXPERIMENTAL DEVICE}

This paper is to a certain concentration of the mixture of ethanol and water sent to the plate in the rectification column, the raw material in the rectification column repeated partial gasification and partial condensation, so as to get the expected product operation process To complete this operation process of equipment in addition to rectification, also need to have the reflux condenser irrigation and other auxiliary equipment, plate rectifying column distillation process system schematic diagram is shown in figure 1 [1].

\section{SYSTEM DESIGN}

\subsection{AdvanTrol-Pro Design}

This design adopts the DCS configuration work is done through the configuration software AdvanTrol - Pro the software user interface is good, easy to operate, fully support a variety of control scheme of DCS system configuration work flow chart is shown in figure 2 [2].

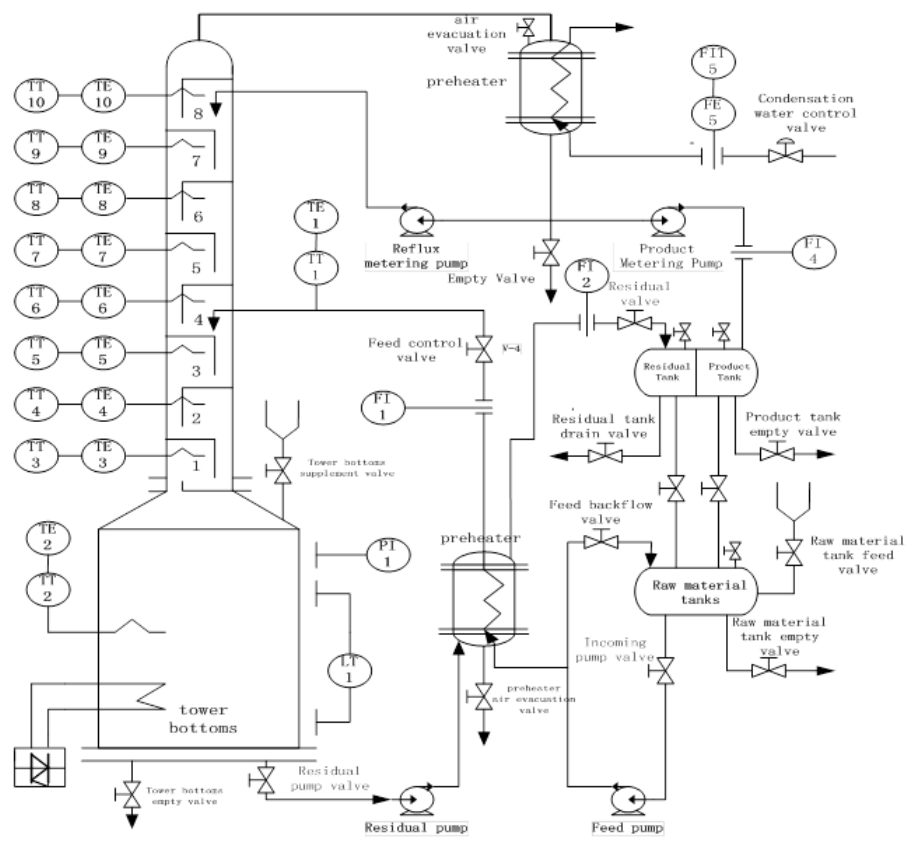

Figure 1: Process Diagram of Plate Distillation Tower 


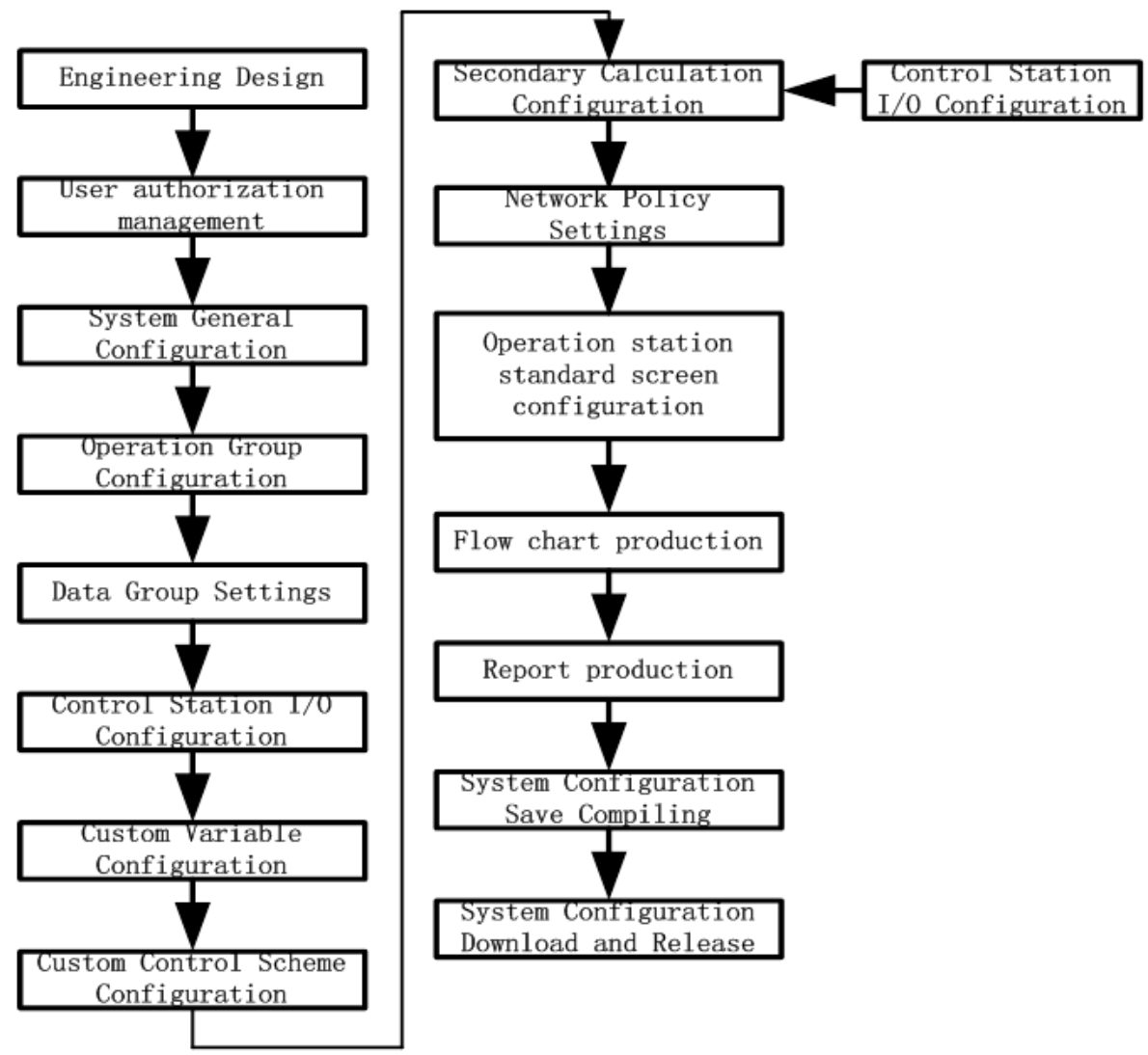

Figure 2: Flow Chart of DCS

The classic PID control algorithm written by AdvanTrol-Pro is shown in figure 3.

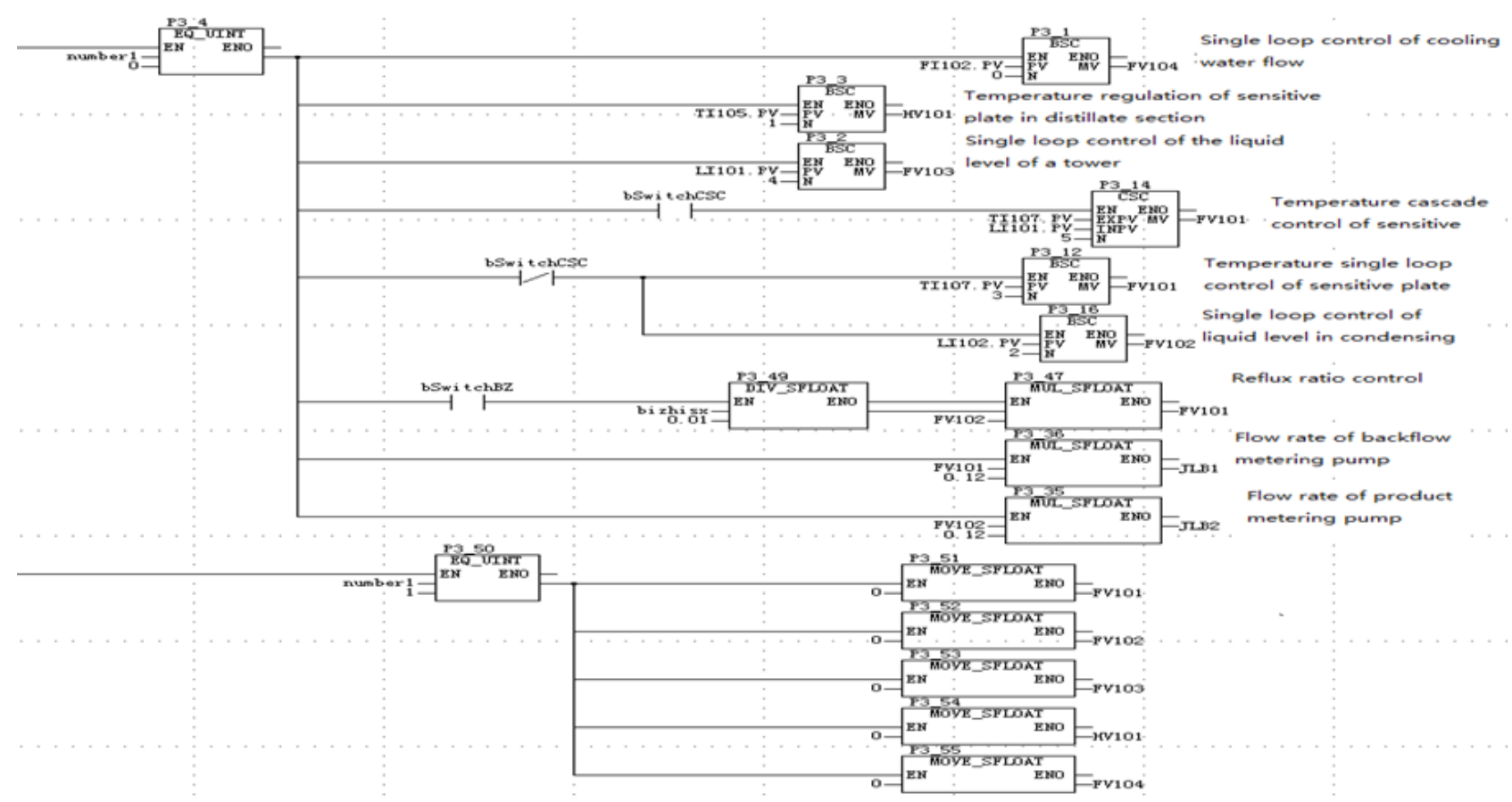

Figure 3: System Program

In this paper, using the AdvanTrol-Pro software completed a monitoring platform for the basic functions, such as real-time curve, curve of history, historical data, the realization of animation, alarming module, reports module, printing module are shown in Figure 4.

Start experiment device power, experiment device software and the experiment software to monitor screen, entered the adjustment screen. Adjust PID parameters until control requirements are met [3,4]. After multiple parameter adjustments, the parameters to meet the temperature control requirements of the distillation section are determined as: $\mathrm{k}=8.6 \%$, integral time is 3.2 minutes, the differential time is 15.6 seconds. The experimental results graph is shown in figure 5 . 


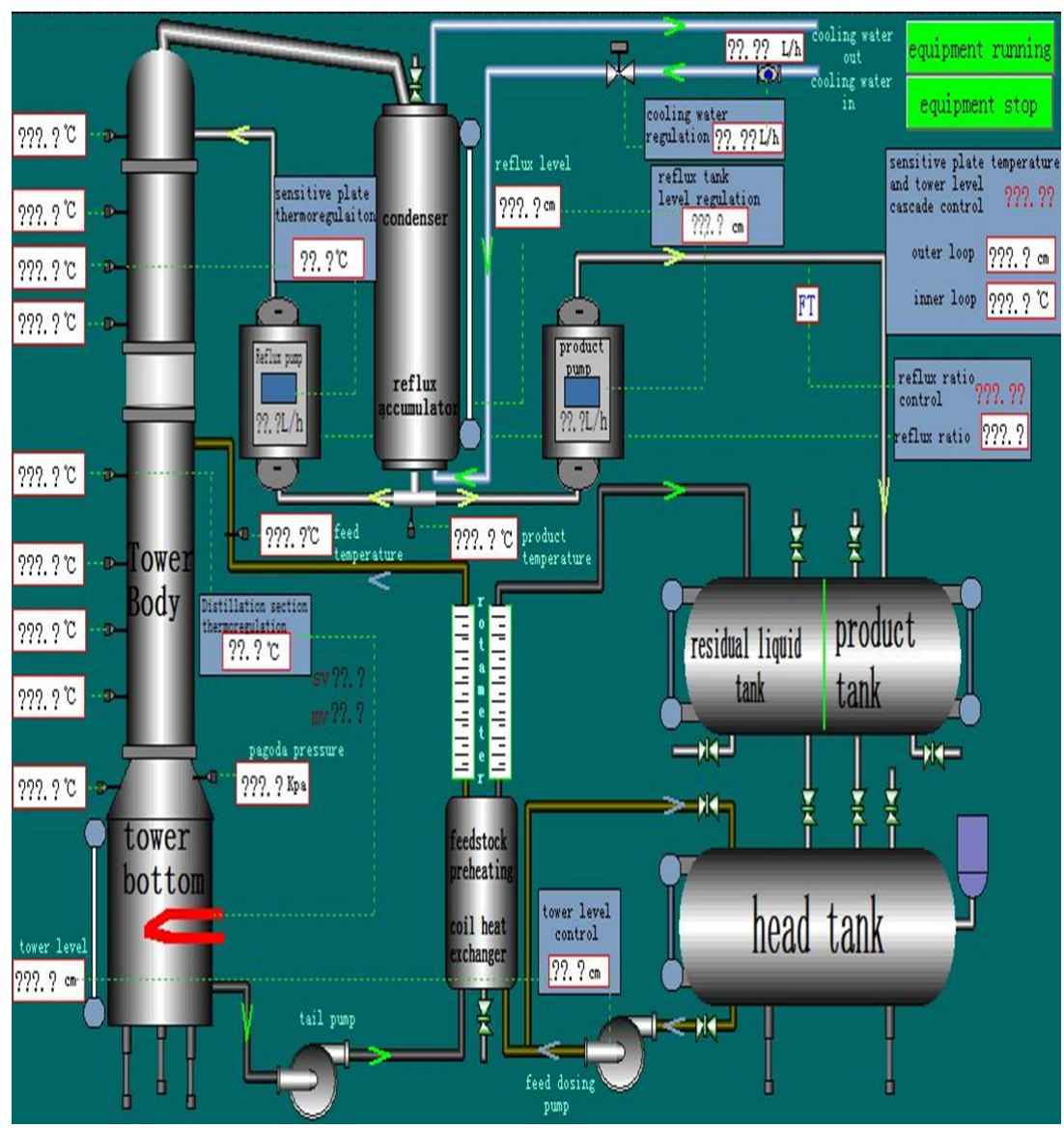

Figure 4: Configuration Interface

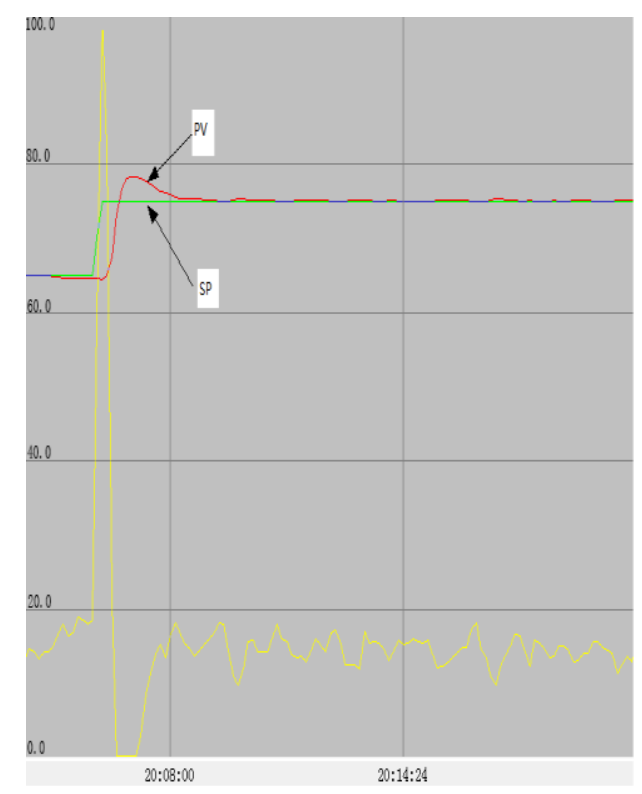

Figure 5: Curve of Temperature

\subsection{Establishment of System Model}

Using the Simulink to write a conventional PID (as shown in Figure 6) and other control algorithm models. The implementation scheme is realized which is based on realization of real-time communication between Simulink and AdvanTrol-Pro by the OPC technology, and a real-time control algorithm in Simulink is established to control the temperature of the distillation tower by direct calling "OPC Read /Write" function in this paper. And clear, visual comparison of the advantages and disadvantages of different control strategies by the trend of different control algorithm [5-8].

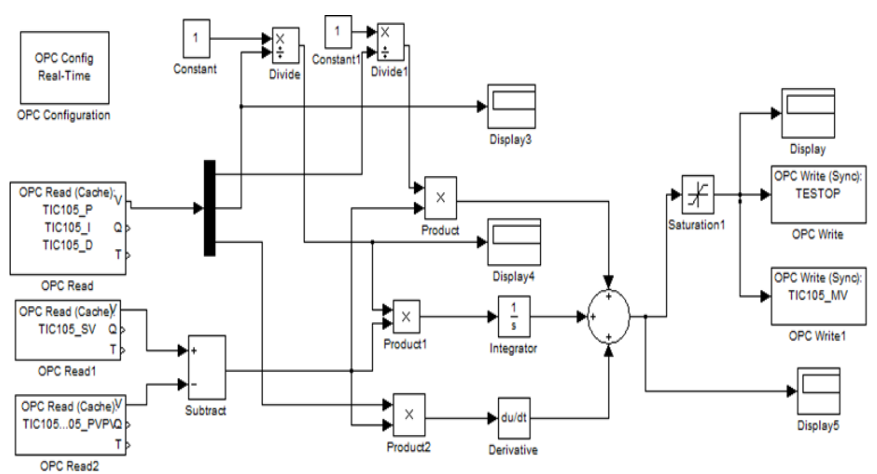

Figure 6: General PID Control Model

\subsection{Experimental Data Analysis}

At this point, Real-time temperature control system for level of tank was designed based on Matlab and AdvanTrol-Pro. Put AdvanTrol-Pro, Matlab and distillation tower into operation, the curve of the actual temperature tracking the desired teperature is gained through AdvanTrol-Pro and Simulink simulation, as shown in Figure 7.

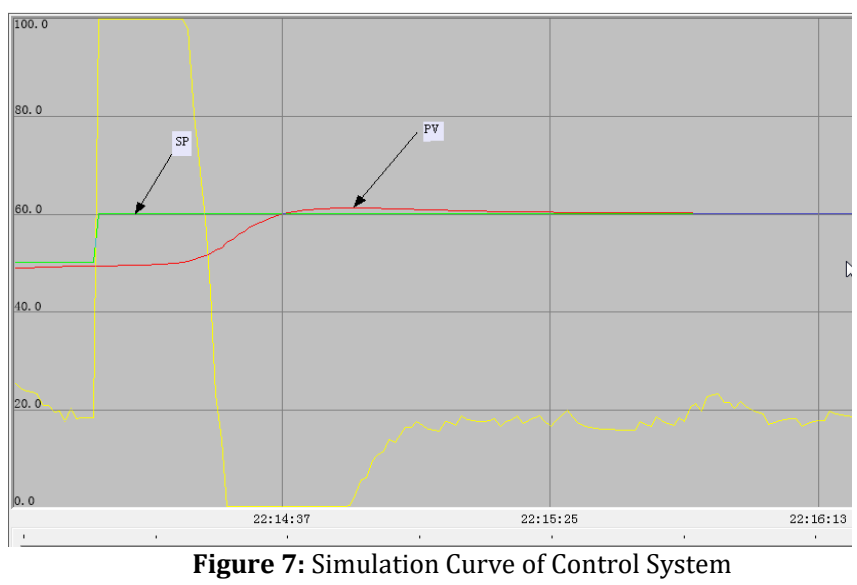


The experimental data of two groups of experiments are controlled by Physical control and Hardware in the loop control, as shown in Table 1.

Table 1: Technical Parameter Table

\begin{tabular}{|lllllllll|}
\hline number & category & $\mathrm{Kp}$ & $\mathrm{TI}$ & $\mathrm{TD}$ & $\mathrm{Tr}$ & $\mathrm{Tp}$ & $\mathrm{Ts}$ & Ess \\
\hline 1 & Physical control & $8.60 \%$ & $3.2 \mathrm{~min}$ & $15.6 \mathrm{~s}$ & $55 \mathrm{~s}$ & $73 \mathrm{~s}$ & $144 \mathrm{~s}$ & $1.80 \%$ \\
2 & $\begin{array}{l}\text { Hardware in the loop } \\
\text { control }\end{array}$ & $8.60 \%$ & $3.2 \mathrm{~min}$ & $15.6 \mathrm{~s}$ & $33 \mathrm{~s}$ & $43 \mathrm{~s}$ & $81 \mathrm{~s}$ & $1.33 \%$ \\
\hline
\end{tabular}

It can be seen from the table that under the same conditions, both control methods can achieve steady state quickly and obtain a good system performance.

\section{CONCLUSION}

In the system, the algorithm analysis and calculation are carried in Matlab, and the real time monitoring, operation, animation and data display are operated in configuration environment with Matlab and AdvanTrol-Pro data exchanged by OPC technology. This transformation technology can effectively combine advantages of configuration real time monitoring conveniently and reflect the system control algorithm analysis and calculation. At the same time, this technology can also effectively solve the configuration software to hardware support. The experimental transformation played a better demonstration effect.

\section{REFERENCE}

[1] Li, H. 2000. Plate distillation column [M]. Beijing: chemical industry press.

[2] Liankui, D. 2012. Process control engineering [M]. Beijing: chemical industry press.

[3] Xuemei, H., Bin, Y., Jun, X.L., Fujiang, J. 2014. Based on jx-300xp DCS chemical distillation tower network experimental teaching platform [J].
Laboratory research and exploration, 33 (09), 10-13.

[4] Anlun, J. 2010. Design and implementation of paper automation control system based on DCS [D]. Shanghai jiaotong university.

[5] Jie, W., Wei, T. 2010. Application of fuzzy PID in DCS based on OPC and MATLAB [J]. Computer measurement and control, 18 (10), 2275-2277.

[6] Quan, S. 2006. The Communication Between KingView and Matlab.Journal of Shang hai Institute of Technology, 4, 286-289.

[7] Yun, H. 2008. The Data Exchange Technology between Matlab and Configuration Software WinCC.Journal of East China Jiaotong University, $25,43-46$

[8] Er-chao, L., Wei-rong, L., Wei, L. 2008. An easy real-time online simulation method base on Wincc and Matlab. Experimental Technology and Management, 25, 69-71.

\section{ABOUT AUTHOR}

Zhu Jian_jun was born in1973.He received master's degree from Dalian University of Technology. He is an professor in Jilin Institute of Chemical Technology now. At present, the main research directions are intelligent control and computer-aided design. 